\title{
A Mechanical Source of Turkish Music from Eighteenth-Century London
}

This article concerns a musical clock that was manufactured in London around the year 1795 bearing the signature 'Markwick Markham Borrell'. The word 'clock' in this case is something of an understatement; the piece is a spectacularly multi-faceted piece of craftsmanship, whose intricate decoration and especially the automaton sea scene are works of art in their own right, as can be seen from fig. 1. However what makes it of particular interest to musicians is that along with the timepiece, automaton and bell-playing movement with four melodies, the case contains a miniature organ driven by a mechanism into which are programmed eight additional melodies. These eight are not named anywhere on the clock and have so far not been identified, but there are strong contextual grounds to suppose that six of them originated at the Ottoman court, probably in what we now call Istanbul. In other words, although these tunes were installed in London, presumably by London craftsmen, they are quite unlike the European style of exotic oriental representation known as 'Turquerie' that was fashionable at the time and designed for European taste and consumption. ${ }^{1}$ They are likewise equally distinct from its musical counterpart, the alla turca style familiar in the work of Mozart and his contemporaries, though aspects of this context are explored below. ${ }^{2}$ Rather it will be argued that they are genuine Ottoman melodies, put onto a device that was made for export and hence intended for a

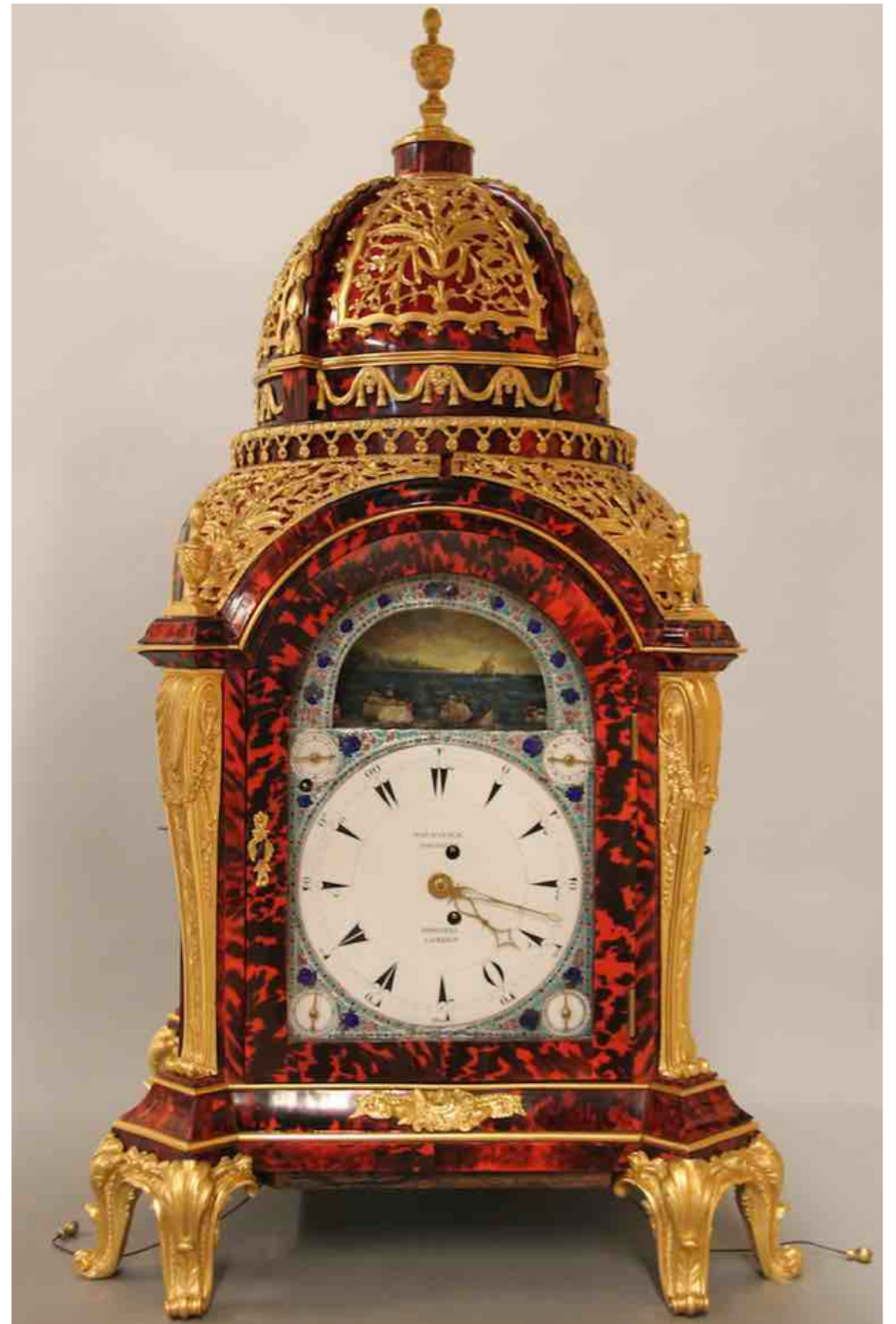

Fig. 1

\footnotetext{
${ }^{1}$ See Williams, Haydn: Turquerie: An Eighteenth-Century European Fantasy (London, 2014); also Meyer, Eva: 'Turquerie and Eighteenth-Century Music', Eighteenth-Century Studies 7/4 (1974), pp. 481-2.

2 For the most recent of the extensive writing on this subject see Wolff, Larry: The Singing Turk: Ottoman Power and Operatic Emotions on the European Stage from the Siege of Vienna to the Age of Napoleon (Stanford, 2016); also Hunter, Mary: 'The Alla Turca Style in the Late Eighteenth Century: Race and Gender in the Symphony and the Seraglio', in Bellman, Jonathan (ed.): The Exotic in Western Music (Northeastern UP, 1992); also Bellman, Jonathan: The Style Hongrois in the Music of Western Europe (Boston, 1993), pp.25-45.
} 
Turkish rather than European audience.

If so, then this organ preserves possibly the earliest example of a non-Western music to survive in sounding rather than notated form. At the same time, the instrument embodies the story of how its music came from Istanbul to Georgian London, just a few miles from where the oratorios of Handel were still in vogue and Haydn was making his debut, and was then exported straight back again. This Borrell clock - recently restored in Utrecht and henceforth referred to as $\mathrm{BU}$ - is therefore a unique witness to a complex tale of cultural interaction, as well as a sounding source for an essentially oral tradition that went otherwise unrecorded until the twentieth century.

The study of BU as a source of historical music presents a number of teasing challenges. Unlike written documents, clocks preserve their music via mechanisms that are susceptible to not just the naturally corrosive passage of time but also successive human interventions of maintenance, restoration or modification. These interventions are generally motivated by the immense value of these astonishingly beautiful devices as objets d'art, rather than as repositories of musical information and a modern restorer must take them into account too when establishing what the original state of the music might have been. A further peculiarity of BU and other clocks like it is that a relatively small number are owned by museums or other institutions that routinely allow public access, with most being owned by private individuals. Respect for the privacy of these owners means that it is impossible to reference them or even identify them as would be normal with a written source, since their location is confidential and they are not open to public inspection; and the situation is complicated still further by the fact that they change hands quite regularly, at least in comparison to musical manuscripts. We are therefore grateful to the owner of this particular clock for allowing us access to it.

Many musical clocks were produced in England in the second half of the eighteenth century and were far more than chiming novelties. ${ }^{3}$ Mechanical devices were the only way of reproducing music without a human performer and as such stood at the cutting edge of the technology of the day, with some of the more elaborate clocks embodying real musical ambition. There are several surviving mechanical organs built into clocks by Charles Clay, for example, that play pieces especially written for them by Handel. ${ }^{4}$ These are substantial compositions that resemble movements from keyboard sonatas; original compositions on a comparable scale by Haydn, Mozart and Beethoven, among others, were incorporated into similar devices made elsewhere in Europe. Organ clocks such as these are a comparative rarity though; those that sound their music on tuned bells were made in greater numbers and the surviving examples typically preserve a repertory of favourite marches, airs, hymns and dance melodies.

\footnotetext{
${ }^{3}$ For extensive and detailed information on musical clocks see Haspels, Jan Jaap: Automatic musical instruments: their mechanics and their music 1580-1820 (Utrecht, 1987); Ord-Hume, Arthur W. J. G.: The musical clock: musical \& automation clocks \& watches (Ashbourne: Mayfield Books, 1995); and White, lan: English Clocks for the Eastern Markets (Ticehurst, RHA, 2012).

${ }^{4}$ For full details see Di Sandro, Massimo: Macchine musicali al tempo di Händel: Un orologio di Charles Clay nel Palazzo Reale di Napoli (Florence: Leo Olschki, 2012); Dirksen, Pieter: 'Twenty Pieces for a Musical Clock (ca. 1738) by George Frideric Handel', Notes, 2nd Series, Vol. 46, No. 4 (June 1990), p.1058.
} 
London makers primarily served a home market but they also benefitted from a substantial export trade, which was at its peak during the 1780 s. ${ }^{5}$ Some of this trade was with Britain's European neighbours - France, the Netherlands and Germany in particular had their own thriving clock-making traditions - but much was with destinations further afield, which included China, India and the Ottoman Empire, then generally referred to as 'Turkey', where many are still preserved. The clocks for 'Turkey' in particular are notable in that they are for the most part tailored specifically to suit the demands of the Turkish market, in ways that make them immediately recognisable. There is a characteristic domed design based on the shape of a mosque (see fig.1) and in deference to Islamic law there are no representations of human figures on them, whereas people in figurative scenes are common on clocks for the European market. ${ }^{6}$ Most obvious of all are the numbers on the main clock dial, which take a form known as 'Turkish numerals', a stylised form of the numerals used in the Arabic script then used in Turkish (clearly different from, and not to be confused with, the 'Arabic numerals' that were, and still are, in common use in Europe). The clocks manufactured in London for the Turkish market, then, are for the most part clearly identifiable and betray a sensitivity to Ottoman and Islamic cultural values, no matter how practical or commercially orientated it was. $^{7}$

\section{Tunes named on 'Turkish market' clocks}

The majority of these export clocks have chimes to mark the hours, but there are some that go beyond this and are properly 'musical', in that they play recognisable melodies; all those known to the present study are listed in Appendix A. These are of particular musical interest because the titles of the tunes they are supposed to play are in nearly all cases engraved onto the face, usually on a subsidiary dial that allowed each to be selected and played independently of the timekeeping mechanism (see fig.2). Most intriguingly of all, over a third of the clocks in Appendix A bear tune titles that are clearly Turkish. It should be

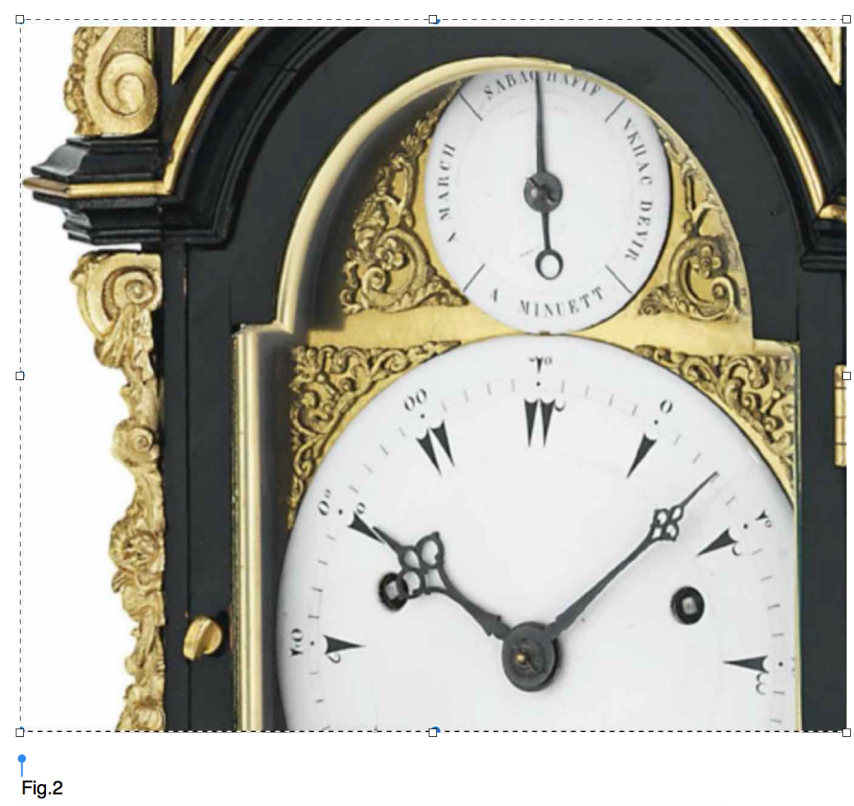

\footnotetext{
${ }^{5}$ For a detailed account of this, see Smith, Roger and Thompson, David: 'Vulliamy Musical Clocks for the Turkish Market', Antiquarian Horology, 21/2 (1993), pp.118-31.

${ }^{6}$ For details of this kind of decoration see Smith and Thompson 1993, p.120; also Kurz, Otto: European Clocks and Watches in the Near East (London: Warburg Institute, 1975) pp.85-6.
${ }^{7}$ The situation is complicated in that in the intervening years since the eighteenth century, many 'Turk- ish' clocks have been returned to Europe by way of trade and have been subsequently altered, char- acteristically with their Turkish numerals changed for resale in Europe. See Smith and Thompson 1993, p.120 n.8.


stressed that the 'Turkish' tunes themselves are now almost completely inaccessible; on those few occasions when a clock with these titles has been available for study, they have not been played clearly enough to draw any confident stylistic conclusions, as will be discussed below. Nevertheless, the fact that even these few fragments of the Turkish language found their way into clockmakers' workshops in eighteenth-century London is extraordinary and suggests an informed acquaintance with the world of Ottoman court music. The nature of the titles further points towards precise aspects of the Ottoman court repertory, which in in turn strengthens the case for proposing that the unnamed tunes on the BU organ that sound 'unwestern' are genuinely Turkish.

Three categories of tunes can be distinguished on the clocks manufactured for export to the Ottoman Empire. The first category - English titles suggesting English tunes, for example 'Lovely Nymph', or 'A Minuet'- mostly consists of the same names as are routinely found on clocks for the home market. There is therefore no reason to suppose that any of them have any connection with the Ottoman repertory, although they do raise the fascinating prospect that English popular airs and dances were ringing out in parts of the Ottoman Empire on a regular basis, a remarkable thought but one that lies outside the scope of this study.

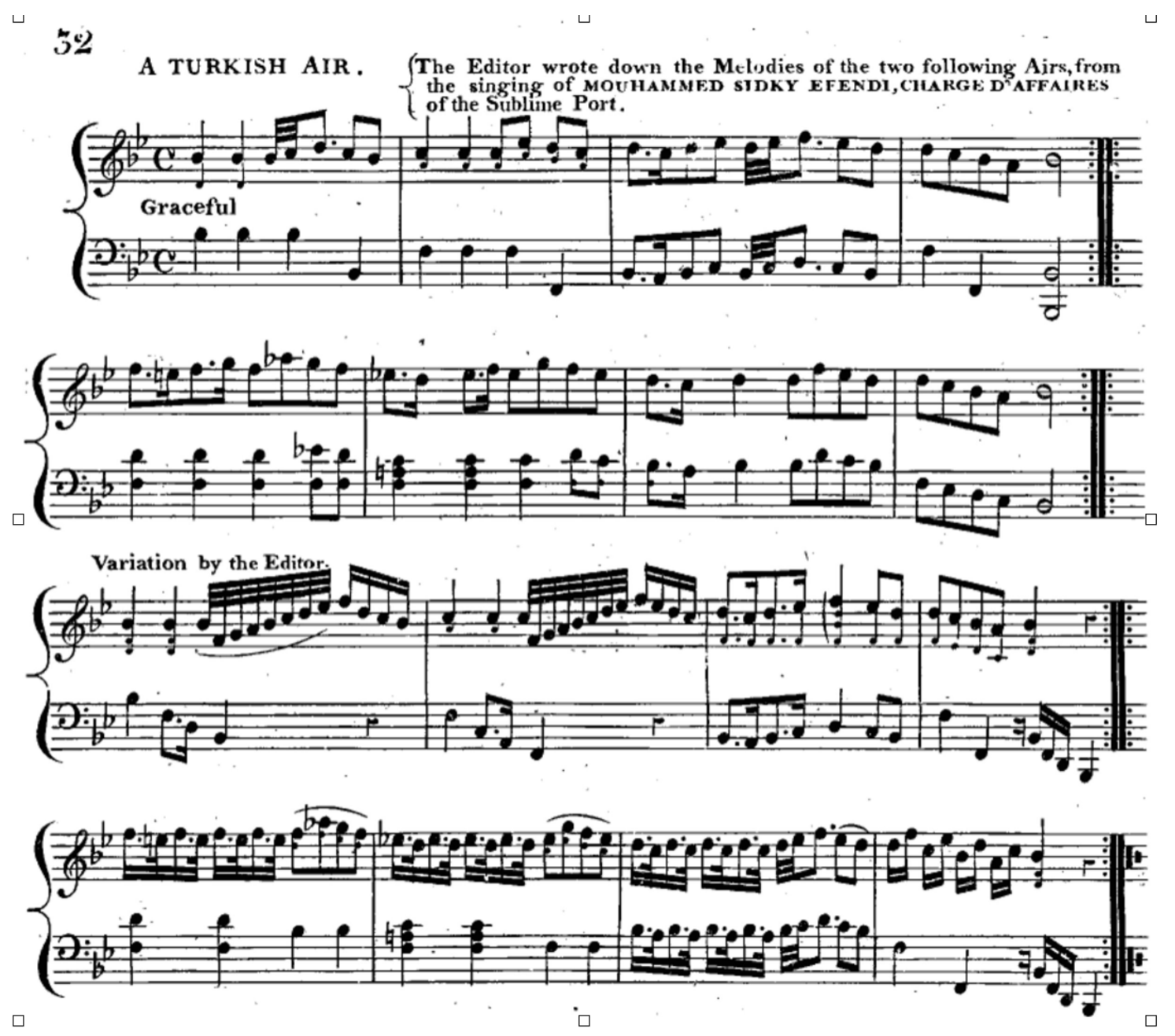

Ex.1 Edward Jones, Lyric Airs, 'A Turkish Air' 
The titles in the second category are also plainly English, but they name exotically national tunes. Many of these, not just 'Dance Turk', but also 'Greke Song', 'Air Moldave' or 'Air Valaque' (in modern Romania), are from Ottoman regions. They reflect a romantic vogue for tunes from exotic locations that also expressed itself in a body of printed music from the same era, such as Haydn's Scottish song arrangements from the $1790 \mathrm{~s}^{8}$ and Edward Jones's Lyric Airs (1804), 'consisting of specimens of Greek, Albanian, Walachian, Turkish, Arabian, Persian, Chinese and Moorish National Songs and Melodies'. However, though the material in the Lyric Airs is extensively annotated and authenticated by a long introduction and impressive-sounding rubrics such as 'written down from the natives singing it' (p.30), most of it looks uncannily like traditional European music, like the Turkish Air on p.32 (ex.1) that despite the editor's certificate of authenticity looks remarkably English. A similar phenomenon has been documented with the 'Hindustani Airs' that appear in many English publications from around the same time. ${ }^{9}$ It may be too much to hope, then, that the national titles on clocks such as 'Dance Turk' might sound any different from the conventional European repertory, although of course there many that still remain to be investigated. It is possible that some may bear traces of the alla turca style used to represent Turkish music, most notably by Mozart in his famous rondo or Haydn in the second movement of his symphony 100, but the elements of this style, though fascinating, are quite clearly distinct from actual Ottoman music..$^{10}$

The titles in the in third category, however, are unambiguously Turkish. 21 out of the clocks listed in Appendix A carry one or more of the names 'Semahe', 'Vkhac Devir', 'Sabac Hafif' or 'Beni Saiket'. These names appear in a number of variant spellings, sometimes in combination with other European tunes (see fig.2) but frequently as an entire repertory in themselves. ${ }^{11}$ The names are invariably written in Latin script, in spite of the careful design of the clock and the Turkish numerals on the face, which might suggest that they were an English affectation like the generic titles discussed above. However three of them have specific musical meanings that were current in the sophisticated art music of Istanbul the time, indicating something more than a purely imaginative connection with the Ottoman practice and terminology.

The title 'Semahe' (henceforth spelt with its conventional modern Latinisation, 'semai') is not derived from a song or verbal text but is rather a label for a specific compositional genre. It is of particular interest because the semai genre is closely associated with the high culture of Ottoman court music and Sufi ritual, where it served a particular function as an overture to the extended suite of songs and instrumental pieces known as a fasil. A large number of

\footnotetext{
8 These appear in various collections, the earliest being A Selection of Original Scots Songs, in Three Parts, the Harmony by Haydn, part 2 (London, William Napier, 1792).

${ }^{9}$ For a full account of these, see Farrell, Gerry: Indian Music and the West (Oxford: OUP, 1997), pp. 28-44.

${ }^{10}$ See Bellman 1993, pp.25-45.

11 The consistency of these names across clocks by a variety of makers reflects the way the manufacture of musical mechanisms was often contracted out to one particular firm, Thwaites and Reed; see Ord-Hume 1995, p.72 n.17, also Kurz 1975, pp.86-7.
} 
broadly similar pieces survive from this period, any of which might have served as a model for a clock, but this typical example was composed by Sultan Mahmud I, an approximate
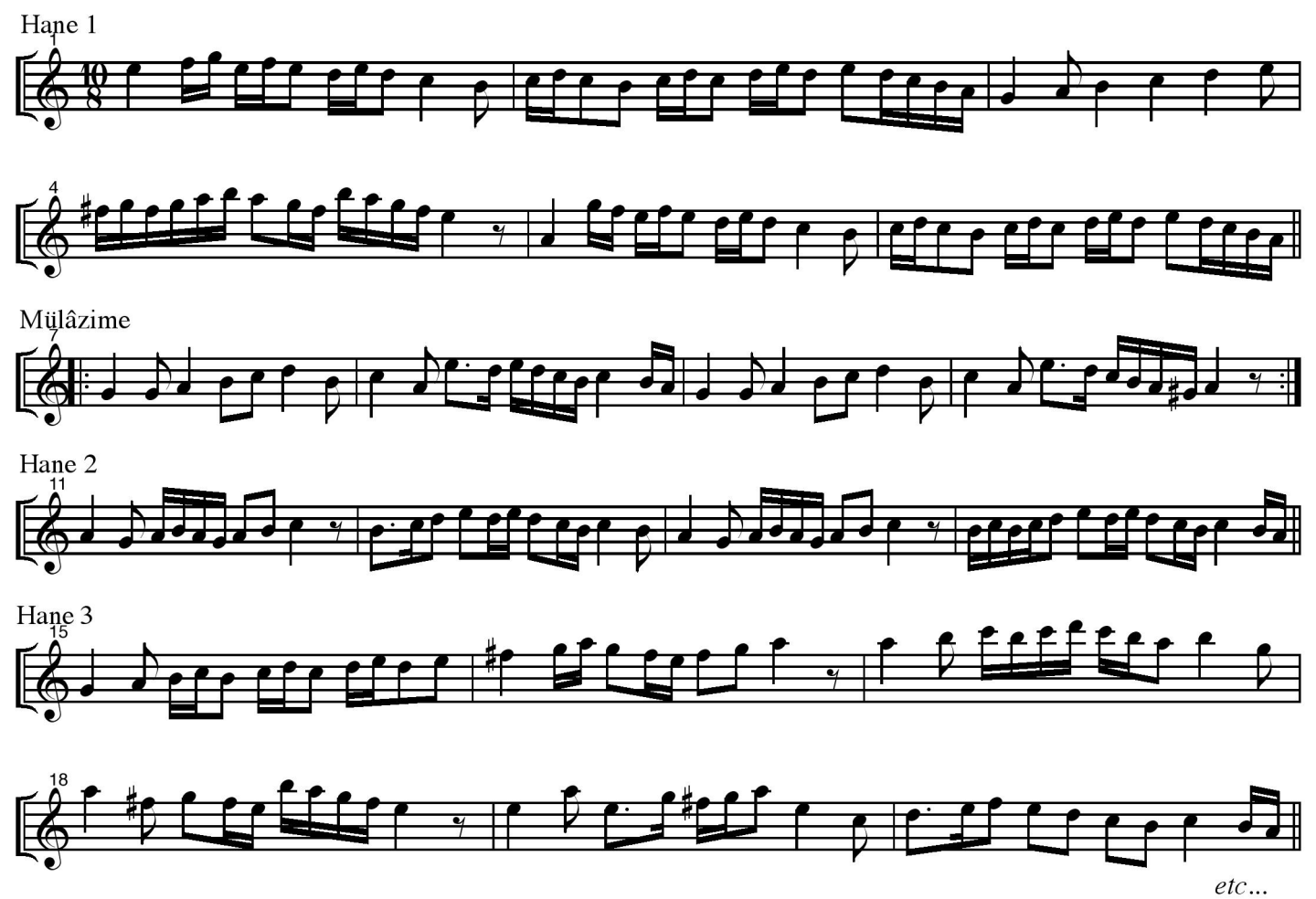

Ex.2. Sultan Mahmud I (1696-1754): 'Buselik Saz Semai', extract

contemporary of Handel: ${ }^{12}$

On paper, perhaps the most striking feature of this melody in terms of eighteenth-century English music is its distinctive ten-beat metrical cycle, or $u s u l .{ }^{13}$ Unfortunately, though, a rhythmic feature like this might be difficult to recognise with any degree of certainty on a clock from the period, because the precision necessary to identify such a subtle structure unambiguously is particularly vulnerable to distortion by the mechanical reproduction process, as will be discussed below.

Nevertheless, the melody in ex.2 also exhibits a number of other distinctive Turkish characteristics that might still be identifiable if it were programmed into an English clock. Unlike most popular English melodies of the time, it unfolds as a long and continuous progression, without symmetrical answering phrases, rhythmic motifs or repetition. It is also typically scalar, with no arpeggiation or large intervals, and notably lacks the conventional cadential

\footnotetext{
${ }^{12}$ See http://www.neyzen.com/nota_arsivi/02_klasik_eserler/016_buselik/buselik_ss_sultan_1_mahmud.pdf. Mahmud I (1696-1754) is not the only Sultan credited as a composer; others from this era include Selim III (1761-1808) and Mahmud II (1785-1839).

13 The full name of this usul is aksak semai, distinguishing it from two others that might be designated by the title 'semai', the 'yuruk semai' consisting of six beats and the plain 'semai' consisting of three; for details see Aydemir, Murat: Turkish music makam guide, ed. and trans. Erman Dirikcan (Istanbul: Pan Yayincilik, ca.2010), pp.210-11.
} 
formulae associated with European harmonic music. Lastly, there is the overall structure; the piece consists of a succession of distinct sections, marked on the transcription using the Turkish term hane, each followed by a refrain, marked using the Turkish term mülâzime. ${ }^{14}$ The resulting structure is extremely unusual in European music and certainly not part of the alla turca style, but it an almost universal feature of the formal instrumental compositions associated with the Ottoman fasil.

'Sabac hafif' and 'Vkhac Devir' are, like 'Semahe', generic musical descriptions rather than anything more poetic. Both titles consist of the name of a makam - a concept that loosely corresponds to the European idea of 'mode' - followed by a rhythmic designation. In this way they function in much the same way as a generic European title like 'Allegro in Bb' and the use of this abstract formula once more connects them with the sophisticated instrumental repertory of the fastl; the majority of the 351 pieces in the Cantemir collection of $c a .1690$ use the same convention. ${ }^{15}$ Compositions in this repertory also exhibit the distinctive Turkish melodic style and hane/mülâzime structure noted above in connection with the semai, so that we might expect to find similar traces of them if the melodies were programmed into a clock, even if the details of the rhythm had been compromised.

The 'Sabac' part of 'Sabac hafif' refers to a makam whose microtonal intervals fall between the notes of the Western tempered scale, so to find it specified on clocks made in eighteenthcentury London is especially intriguing. ${ }^{16}$ Several contemporary Western travellers commented on the intricacies of Turkish tuning in considerable detail, but it seems extremely unlikely that traces of 'sabac' might ever be identified on any English clock. ${ }^{17}$ Even if the 'sabac' intervals were intended, the inharmonic nature of bell sounds means they would be very difficult to hear with any certainty and even more so after the inevitable distortions in tuning brought about by the passing of over two centuries. ${ }^{18}$ Another consideration is that the numerous clocks that name English tunes alongside 'Sabac hafif', like that in fig.2, have only a single set of bells that served for all the tunes. ${ }^{19}$

${ }^{14}$ This is the exact equivalent of the modern term teslim; see Wright, Owen (ed.): Demetrius Cantemir. The Collection of Notations (London: University of London, SOAS Musicology Series Volume 1, 1992), part 1, p.xxi.

${ }^{15}$ This collection includes a piece that could be described as 'Saba hafif', though there is no reason to identify it specifically with a name that was put on clocks over a century later; see Wright 1992, pp. 210-11.

${ }^{16}$ For a full account of makam saba see Aydemir 2010, pp.196-8.

${ }^{17}$ See John Hawkins's footnote to the music of 'A Turkish Concerto, called Susudil' on p.20 of Edward Jones's Lyric Airs (1804) and the comments by Guillaume Villoteau, to be discussed below.

${ }^{18}$ For the acoustical properties of bells, see Marolt, Matija, Lefeber, Marieke: 'It's time for a song transcribing recordings of bell-playing clocks', Proceedings ISMIR 2010, pp.333-8.

19 'Hafif' literally means 'light' and is still used by modern Turkish musicians to mean 'fast'. In the eighteenth century it referred to a particular usul that was 32 beats in length. This is by no means long by the standards of the Turkish art music of the time and pieces in hafif are relatively common; see Wright 1992, pp.xviii-xxi. 
The 'Vkhac' in 'Vkhac Devir' presumably corresponds to the modern 'makam ussak', whose intervals might likewise be hard to identify precisely, while 'Devir' simply means 'cycle' rather than any individual meter. ${ }^{20}$ Nevertheless the formulaic title still implies a formal instrumental composition like 'Sabac Hafif' or 'Semahe', such that we might expect to find traces of the same stylistic and structural characteristics as were noted above.

The fourth title, 'Beni Saiket', probably indicates a song, so that it is not possible to infer any specific musical characteristics. However, if the bell clocks bearing the other three titles were indeed programmed with Ottoman melodies, then traces of them might be recognisable from their melodic style and hane/mülâzime structure, even if the rhythms and the modal tuning have been compromised. This is a fascinating possibility but one that is still frustratingly hard to verify. It has been possible to hear the music on just one clock with these titles in the course of the present study, Christies 5327/354, whose dial bears the names 'SABAC HAFIF', 'A MARCH', 'VKHAC DEVIR' and 'A MINUETT' (see fig.2). ${ }^{21}$ Unfortunately it would only play three of the tunes during the time that it was accessible. Two of them are pretty convincingly a march and a minuet by virtue of their meters and regular phrase structures, but the third has longer phrases and a less obvious meter, as can be seen from the transcription in Appendix B. It is tempting to interpret this latter as suggesting a Turkish usul, but the inconsistent pulse and meter could result from purely mechanical irregularities; the tunes are 'programmed' onto pinned barrels, along the same principles as a modern musical box, and missing or displaced pins can give the impression of an uneven meter, as can distortions in the frame determining the height of the keys above the barrel surface, or variations in the speed at which the barrel rotates.

Structurally, the music is in a short AAB form which could point as equally towards European binary repeats as towards any kind of hane/mülâzime principle. The melody does seem to unfold as a continuous progression, without symmetrical answering phrases, rhythmic motifs or repetition, unlike the minuet and the march. How much this is due to mechanical distortion may become clearer if more renditions of these 'Turkish' titles become accessible, but in the meantime the evidence is inconclusive. Nevertheless, this melody is not convincingly European either, unlike the other two, and the possibility of it being genuinely Turkish seems significantly increased by the unique evidence of BU.

\section{The tunes on the Borrell organ clock}

None of the tunes on BU - neither the four played on the bells, nor the eight on the organ are named, so there is no external indication that any of them might have been Turkish, nor any direct means of connecting them with the Turkish titles discussed above. However, six out of the total of eight tunes on the organ are quite unlike anything in the normal English repertory and there are strong grounds for supposing that they were genuinely Turkish in ori-

\footnotetext{
${ }^{20}$ For a full account of makam ussak, see Aydemir 2010, pp.108-10.

${ }^{21}$ Although clocks with interchangeable barrels existed, there are no known examples with Turkish tunes on them. Since otherwise altering the music would have been a complex procedure, it is assumed here that the tunes on this clock match the names engraved on the face.
} 
gin. This is a bold claim to make on the basis of musical style alone, but when taken together with the date and context of the clock the evidence seems persuasive and is worth reviewing in some detail.

There can be little doubt that BU was intended for the Turkish market since, as can be seen from fig.1, it shares the typical dome shape and Turkish numerals of the many other clocks that were exported there. ${ }^{22}$ In addition, the name Markwick Markham Borrell is one that appears on a great number of Turkish market clocks. The 'Markwick Markham' part seems to have been fictitious, ${ }^{23}$ but Henry Borrell was a prolific London clockmaker for the Turkish market who was active between 1795 and $1840 .{ }^{24} \mathrm{BU}$ has previously been dated to $c a .1790$; however a paper glued to the bellows carries the date 1793, showing that it cannot have been made before then. ${ }^{25}$

The clock was recently restored in the workshop of Museum Speelklok in Utrecht. As well as a general revision of all the clock mechanisms, including the bell-playing movement and the organ movement, the wind chest, bellows and pipework were restored. The pre-existing pipework was clearly not original and required extensive alteration, but the accuracy of the present restoration is confirmed not only by the musical plausibility of the resultant tunes but also by the logical arrangement of the pipes within a restricted space and the original interstices in the top of the wooden case.

The mechanism in the organ is programmed to play eight tunes, indicated on the face not by titles but by the numbers one to eight, a frustrating procedure in view of its peculiar musical interest but one that is shared by one of the four other surviving English organ clocks for the Turkish market. ${ }^{26}$ The tunes will therefore be referred to here (and in Appendix B) simply as B1 through to B8.

Two of them sound exactly like tunes from the domestic English clock repertory, even though they cannot be identified. From their clear meter and regular phrasing, B3 sounds like a jig and B6 sounds like a minuet and there is no reason to suppose that they have any Turkish connection at all; pieces called 'jig' or 'minuet' are commonly found on Turkish market clocks, often alongside Turkish titles as in fig.2. It is worth noting that there are some eccentricities in the 'performance' of even these familiar rhythms, as for example in the last line of

${ }^{22}$ See Smith and Thompson 1993, p.120 and Ord-Hume 1995, pp.212-14.

${ }^{23}$ The Markwick Markham partnership ceased trading around the year 1742, long before BU was made, but the name was retained as a prefix by Borrell and many other London exporters, 'lest the Turks should be startled by new names', as one contemporary put it; see White 2012, pp.345-6. The actual manufacture would have been not by a single individual but by teams of specialist artisans, each of whom contributed specific components, with the name on the face referring to whoever finally assembled the clock and marketed it.

${ }^{24}$ See also White 2012, p.339; Ord-Hume 1995, p.281; Britten 1899, p.706.

${ }^{25}$ The paper also carries the name of the otherwise unknown 'James Learoy'. It is unfortunately not clear who was the original owner of the clock.

${ }^{26}$ Made by Perigal; see Ord-Hume 1995, p.120. The others do indicate the names of their tunes, but these are all clearly English; see Appendix A. 
B3, or the last two lines of B6 (see Appendix B). In the context of this simple music, these can reasonably be assumed to be either pinning errors or mechanical distortions; and it follows that we might expect similar deviations in the other tunes too, perhaps more so if the style was unfamiliar.

Of the remaining tunes, the clearest cases for any representing a Turkish repertory are those of B1 and B2. Rhythmically they are unremarkable, but structurally, both exhibit the hane/ mülâzime structure that is so characteristic of Ottoman instrumental music, as marked in Appendix B. Furthermore in both the opening hane is in the same register as the mülâzime, whereas the second hane is higher in pitch and provides a melodic climax before the return, another typical feature of Ottoman instrumental music.

Within each hane and mülâzime, the melodies are long, have little by way of internal motivic repetition, and proceed almost entirely by scalar motion without arpeggios, large leaps or conventional Western cadential formulae. However, what may perhaps most immediately strike European ears are the modal features, especially patterns based on the interval series semitone-augmented second-semitone known as hicaz, or melodies that in European terms appear to fluctuate between major and minor. ${ }^{27}$ These are wholly consistent with Turkish makam theory and the surviving repertory, but wholly extraordinary in the context of eighteenth-century European music. Taken together with the mülâzime structure and the extended non-motivic melodic progressions, they are convincing evidence that these tunes are directly derived from Turkish models rather than a European invention in the alla turca style.

The rhythms of B8 are somewhat less clear and in order to transcribe it in a regular meter, it has been necessary to 'correct' some of them, especially in the first and last lines. The phrase lengths remain puzzling, with the present transcription inserting a half-bar at the end of each line, but the meter is otherwise plausible and there seems to be no suggestion of any alternative. Moreover the other aspects of the melody still seem convincingly Turkish; the mülâzime structure is clear, the second hane states the melodic climax, there are no obvious motifs, arpeggios or conventional cadences, and the distinctive hicaz pattern is prominent throughout.

B5 likewise needs a degree of rhythmic rationalisation to fit into a regular meter; the last note of the descending scale towards the end of each phrase is consistently short. The structure $\mathrm{AABB}$ with the same phrase ending each section, and the second phrase in the same register as the first - is not quite the expected mülâzime form either. Nor does it resemble a European form though, while the distinctive melodic style and especially its hicaz modal patterns are similar to B1, B2 and B8.

B7 is metrically problematic because it is hard to discern any regular pulse. An analysis of the note durations reveals that they do not clearly cluster around a single value and its multiples, as might be expected if the music could be expressed in quavers, crotchets and minims etc. There is a slight cluster around a duration of 0.12 seconds and just possibly at double this too, so that in the absence of anything else this has been taken as the unitary value of a semiqua-

${ }^{27}$ For a full account of the hicaz tetrachord and makam, see Aydemir 2010, pp.158-62. 
ver in the transcription. Approximating each of the other durations to the nearest multiple of 0.12 - so 0.24 for a quaver, 0.36 for a dotted quaver, 0.48 for a crotchet, etc - yields the somewhat unwieldy rhythms in the transcription given. Two phrases tantalisingly suggest the ten-beat semai cycle of ex.2 in their melodic contour as well as their rhythm, but the rest of the music does not, so that the intention remains obscure. Nevertheless, the structure with its mülâzime and melodic peak in the second hane seems clearly Turkish, as do the melodic progression and hicaz inflections noted above in connection with B1, B2, B5 and B8.

The remaining tune, $\mathrm{B} 4$, is in a clear duple meter but lacks any trace of the hane/mülâzime structure or hicaz pattern. At the same time, it is perhaps more scalar than most English tunes and lacks any stereotypically European characteristics too. Taken on its own, the evidence might be inconclusive, but if the other tunes on BU are Turkish, then B4 may well be too.

\section{Turkish music in contemporaneous European notation}

On the face of it, the idea of eighteenth-century London clockmakers being familiar with genuine Turkish tunes seems improbable, but in fact there were a number of transcriptions of this sort of music circulating at the time. Of particular interest is 'A Turkish Concerto, called Susudil', transcribed in Turkey by John Hawkins 'when on his tour in the Levant' and published in Edward Jones's Lyric Airs of 1804. ${ }^{28}$ The Lyric Airs is a remarkable collection of exotic music, mostly from Greece, Eastern Europe and Asia, arranged for piano solo. Many of its contents, like ex.1 above, are indistinguishable from European music, but the 'Turkish Concerto' is not only substantially longer but also plausibly Turkish in style (see ex.3), certainly infinitely more so than any examples of alla turca style by Mozart or Haydn. The left hand of the piano arrangement is clearly an editorial invention but the melodic style of the right hand looks remarkably similar to that observed in ex.2 above and indeed in the 'Turkish' tunes on BU. ${ }^{29}$ It is surprising that there is no hicaz anywhere, since this pattern is an important feature of the makam called 'susudil' (or in modern terms 'suzidil'), but this may have been a deliberate editorial amendment to render the music more 'agreeably to an English ear', as the footnote in fig. 3 puts it. ${ }^{30}$ This note shows Hawkins to be acutely respectful of the intricacies of Turkish scales, as does his comment 'that there is perhaps no school of music in the west of Europe where it [i.e. musical theory] is more discussed'. ${ }^{31}$ The fact that the hicaz pattern is apparently censored here, but is by contrast very prominent in the tunes on BU,

\footnotetext{
${ }^{28}$ See Jones, Edward: Lyric Airs (London: Edward Jones, 1804), introduction p.24 and main music text pp.20-23.

${ }^{29}$ The 'harmonisation' of Turkish and other non-European melodies was a common practice in transcriptions of the time; see those for example in Aksoy, and the 'Ächt türkisches Musikstück' in Czerny, C.: Wiener Musikalisches Pfennig-Magazin (Vienna, 1835), p.93.

${ }^{30}$ For a full account of makam suzudil, see Aydemir 2010, pp.45-8. The invention of this makam has been attributed to Sultan Selim III; see Aydemir 2010, p.45.

${ }^{31}$ Jones, Lyric Airs, introduction p.2.
} 
A TURKISH CONCERTO, called SUSUDìL.

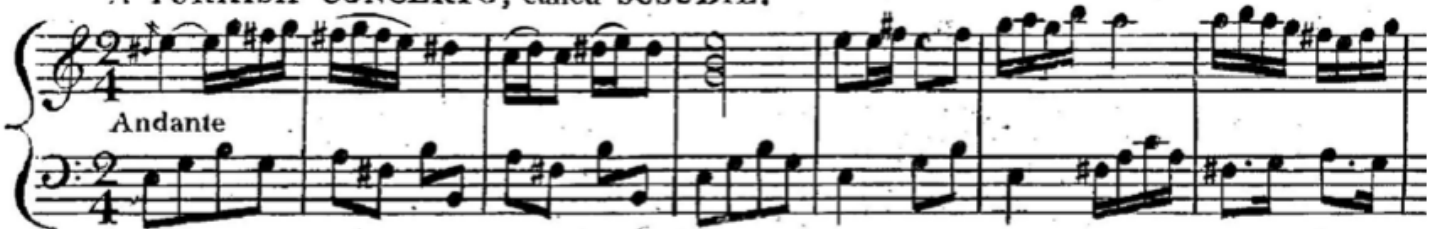

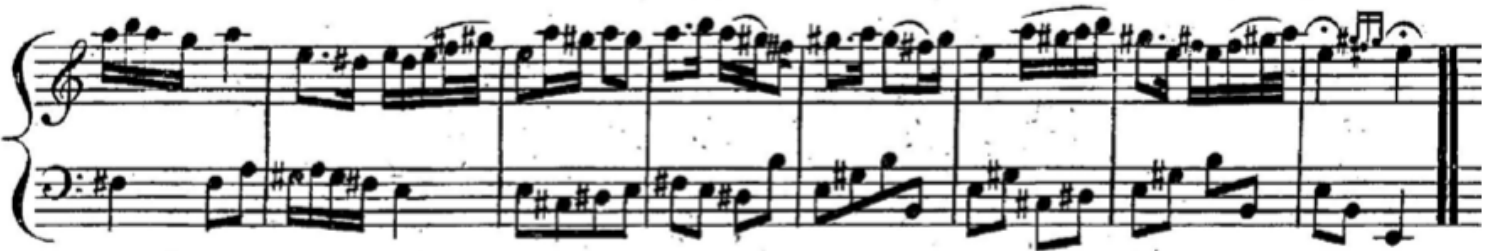

Milaseme.
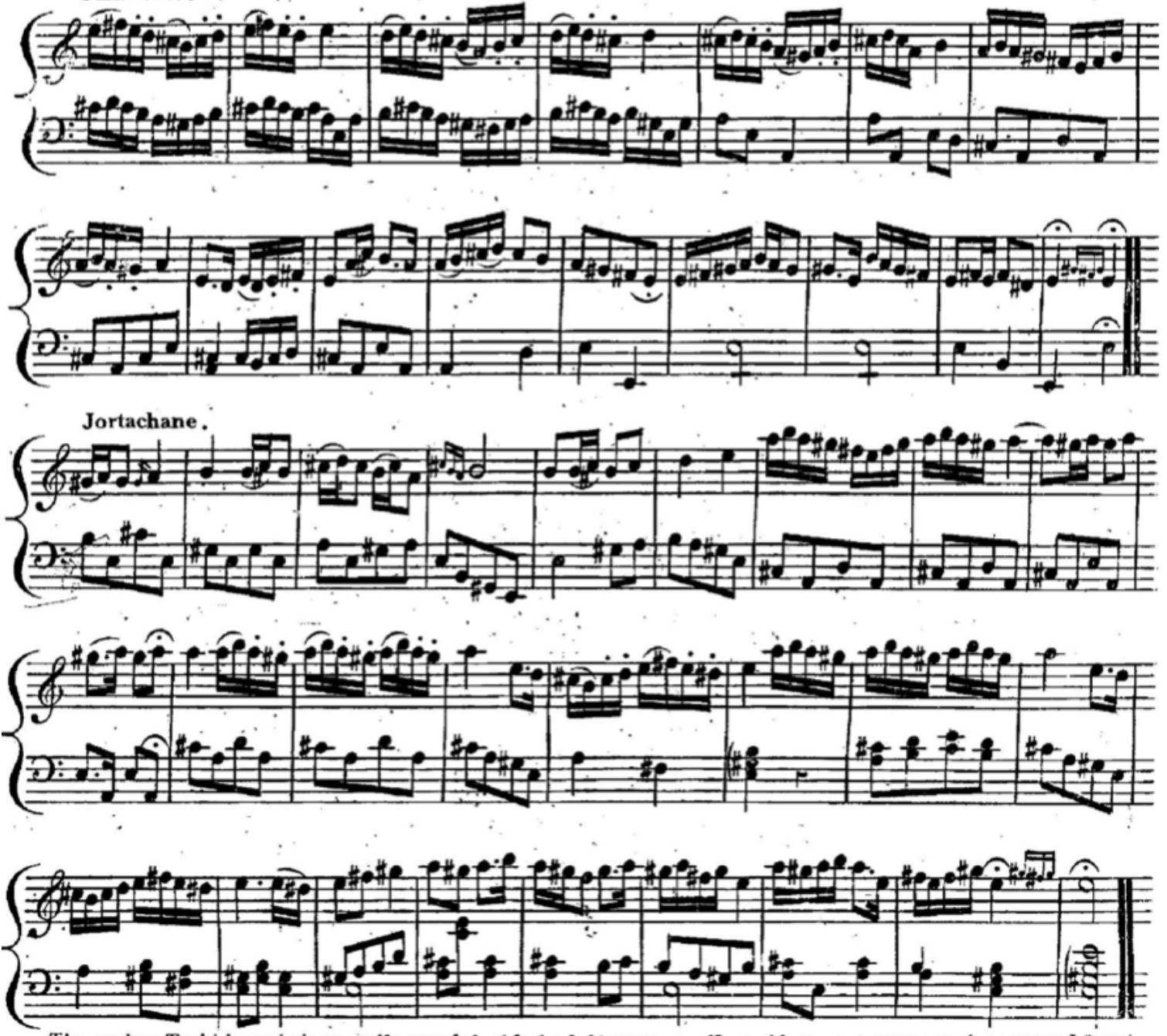

The modern Turkish music is generally crowded with the half-tones, as well as with quarter-tones; ou
ihis pir.. if music very difficult to arrange, so as to adapt it to our scale agreeably to an English ear.

Ex.3 'A Turkish Concerto', extract

seems to support the notion that the latter were intended for a genuinely Turkish audience, 
rather than an English parlour. ${ }^{32}$

Structurally, an editorial understanding of the hane/mülâzime model is made explicit by including the appropriate Turkish terms 'Serchanesi' ('opening hane'), 'Jortachane', (or 'Ortachane', 'second hane'), 'Sonchane' ('third hane') and 'Milaseme' (ie 'mülâzime'). It is interesting though that the written-out repeats are not quite what we would expect from the many examples like ex.3 or those in the Cantemir and other collections, as it may reflect the difficult conditions under which the transcriptions were made. Hawkins was working from live performance, so that the process of writing and rechecking must have meant repeatedly stopping the musician (or musicians) and indicating where he wanted them to go back to. Since Ottoman music was performed from memory, specifying an exact place in a long piece would have been difficult, and combined with the unfamiliar musical style and possibly a language barrier too, the business must have been lengthy, exasperating, and prone to misunderstandings on both sides. An account of a similar process by Guillaume Villoteau, who was collecting music with the Napoleonic army in Egypt at around the same time, tends to confirm this; he describes having to suffer what he calls 'ear-tearing barbaric music' day after day, from morning to night. ${ }^{33} \mathrm{He}$ also describes his frustration with the musicians apparently never playing anything the same way twice; naturally enough, since ornamentation and improvisation play an essential part in this music. ${ }^{34}$

These cross-cultural misunderstandings are important because they must also have applied to the maker who pinned the tunes onto BU. Of particular interest is the 'semai' that starts on the second page of the 'Turkish Concerto' (see ex. 4), since that title is found on so many English clocks. The Lyric Airs sets it out in a duple meter, which is at odds with the specific metrical conventions of the semai genre, which were either a sixbeat or ten-beat pattern as detailed above. However there is much to sug-

32 They are however a major feature of the 'Äcl ches Pfennig-Magazin.

${ }^{33}$ Villoteau, G. A.: De l'état actuel de l'art music l'Egypte: Etat moderne, i, ed. E. F. Jomard (Pal

34 Villoteau 116. For an extensive critique of Vil
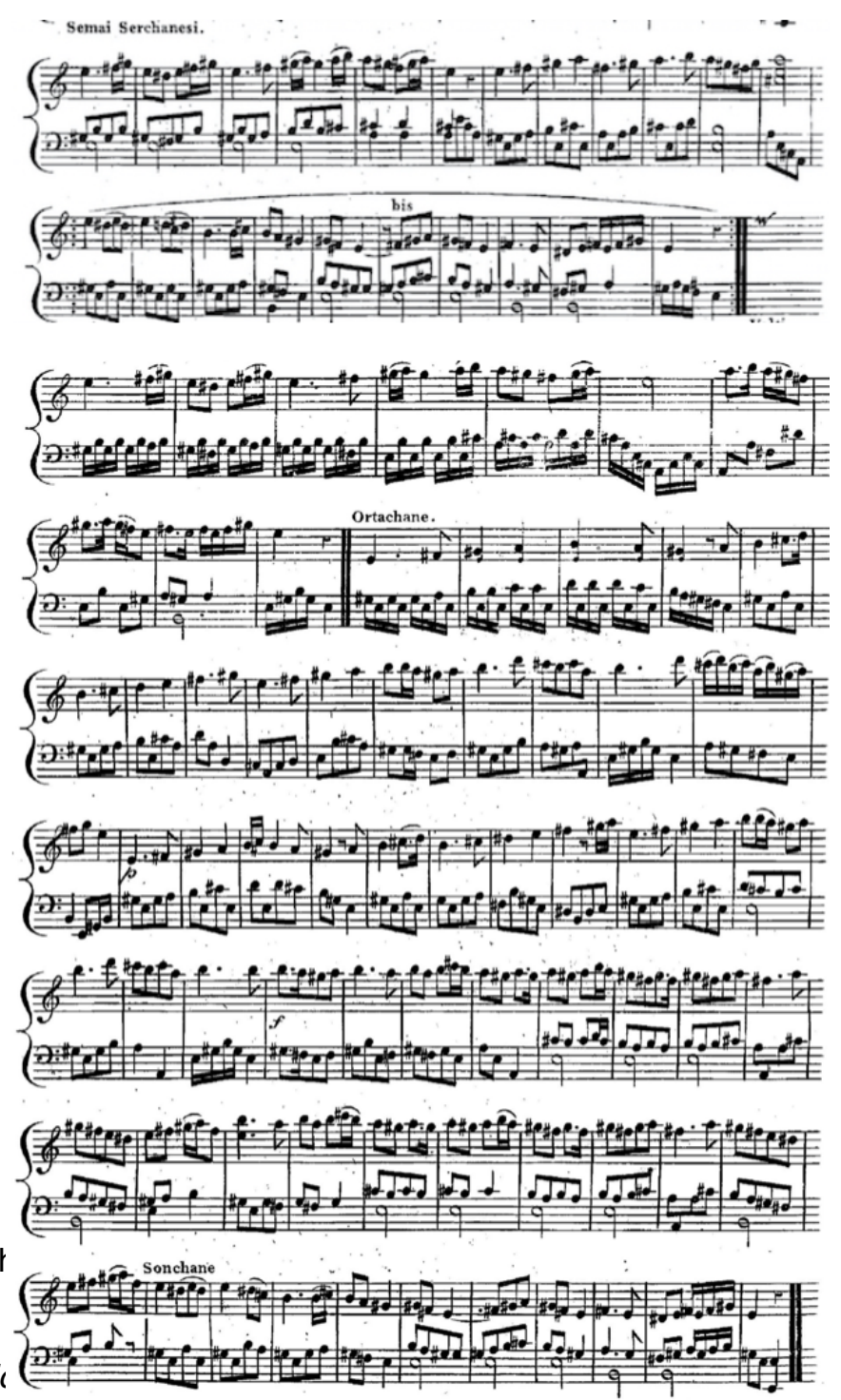

Ex.4 'Turkish Concerto', pp.21-2.

Ruth: Music, Travel, and Imperial Encounter in 19th-Century France (Routledge, 2015). 
gest that the original was indeed in a ten-beat meter, in particular the regular five-bar phrases at the start of the 'Ortachane' (1.4) or the ten-bar phrase in the second line. Moreover the opening phrases of the 'Serchanesi' take the form of a five-bar unit plus a final long note, while the repeated phrase starting at the fifth bar of 1.7 is nine bars long and seems to lack the expected long note at the end, suggesting that it has been elided. To interpret these as vestiges of an original five-bar rhythmic cycle is not to charge Hawkins with incompetence; it is likely that he was simply innocent of the Turkish idea of a rhythmic cycle, since it is not mentioned it in his serious and extensive comments on other alien concepts such as quarter-tones. The practical difficulties involved in transcribing these complex phrases are fertile grounds for confusion and in the absence of the appropriate ten-beat framework to check against, mistakes are almost inevitable. The other surviving transcription of a complete semai from the time, in Toderini's Letteratura Turchesca, shows comparable metrical and structural irregularities. $^{35}$

Similar issues would have beset the artisans who programmed the music into BU. It had not only undergone some kind of initial transcription, but them it must also have been transferred to the medium of a pinned barrel. The present 'performance' therefore embodies an accumulation of the vulnerabilities inherent in those processes and in addition the distortions brought about by an ageing mechanism. For the most part the rhythms and structures on this extraordinary organ clock correspond closely to those of contemporaneous Ottoman music, so that anomalies such as those in B5 and B8 can be plausibly taken to be errors. Taking all this into account makes it slightly more plausible that the strangely skewed rhythms of B7 are indeed the vestiges of a genuine semai; the ends of each mülâzime are suggestive, pieces with this title are found on other clocks, and the Lyric Airs and Toderini demonstrate how such music could be distorted before it ever reached a clock workshop.

Whatever the rhythms of B7 may be, there seems little reason to doubt that the melody is Turkish in origin, along with five of the others on BU. This is perhaps not as implausible as it might seem in 1790s London; after all, the city had been home to the Divan Club, 'exclusive to Gentlemen who had made a voyage to Turkey' and the place where Lady Mary Wortley Montagu's Turkish letters were published and read. ${ }^{36}$ Moreover the Creechurch Lane synagogue (now known as Bevis Marks) is only a quarter of a mile away from the clockmaking district near the modern Guildhall. This is doubly significant since the synagogue not only still maintained its Sephardi traditions and music at this point, but its community played a vital part in the trade with Turkey. ${ }^{37}$ These connections, along with the lively interest that the

35 This time one in the older six-beat meter; see Giovanni Battista Toderini, Letteratura Turchesca (Venice 1787); facsimile in Aksoy, Bülent: Avrupali Gezginlerin Göyzüle Osmanlilarda Musiki (Istanbul, 1994). Jones's Lyric Airs refers to Toderini's book, but not the semai in particular, in a footnote to p.22 of the introduction.

\footnotetext{
${ }^{36}$ See Finnegan, Rachel, 'The Divan Club, 1744-46', EJOS ix/9 (2006) 1-86; the first collection of Lady Mary Wortley Montagu's letters was published as Letters of the Right Honourable Lady M[ar]y W[ortle]y M[ontag]e, written, during her travels in Europe, Asia and Africa... by T. Becket and P. A. de Hondt (London, 1763).

37 See Hyamson, A, The Sephardim of England (London 1951), pp.417-18; the musical practices at the Creechurch Synagogue had been previously noted in the diaries of Samuel Pepys. For the role of Jewish agents in trade with Turkey, see White, English Clocks for the Eastern Markets, p.57.
} 
certain sections of the London public took in 'oriental' music, meant that publications like the Lyric Airs and Toderini's Letteratura Turchesca were probably not the only ones to circulate 'Turkish' pieces in a city that also valued its 'Hindustani Airs'. Establishing whether the 'Semahe', 'Vkhac Devir', 'Sabac Hafif' and 'Beni Saiket' found on so many other clocks are genuinely based on Turkish originals will depend on more examples of these melodies becoming accessible in a recoverable form, which may be a lengthy process. Meanwhile the unnamed tunes on BU stand as the earliest sounding representation of non-Western music to survive and a monument to a remarkable cultural interaction. The distinctive sounds of the hicaz pattern may have been edited out of the domestic piano arrangements in Jones's Lyric Airs but they did indeed sound in the city that still cherished Handel's oratorios alongside Haydn's symphonies, in the ears of explorers, artisans and entrepreneurs. 